DOI: http://dx.doi.org/10.17793/rdd.v4i6.640

\title{
1. ADMIRÁVEL ESTADO DO FUTURO
}

\author{
1. BRAVE STATE OF THE FUTURE
}

\section{Roberta Magalhães Gubert ${ }^{1}$}

Resumo: O presente texto utiliza os elementos de crítica da obra Admirável Mundo Novo, de Aldous Huxley, para pensar e debater a crise e as transformações do Estado contemporâneo. Assim como a obra de Huxley permitiu, sob o ponto de vista da literatura, repensar as iminentes transformações pelas quais o Estado e a sociedade passariam no século XX, antecipando de forma surpreendente muitas características marcantes da sociedade do consumo, o presente texto busca investigar os elementos que impactam de forma mais decisiva a crise que se instala no Estado contemporâneo e as possíveis alternativas para a construção de um novo modelo.

Palavras-chave: Estado Contemporâneo - Crise - Globalização Admirável Mundo Novo - Aldous Huxley

\begin{abstract}
This paper uses the critical elements of Brave New World, by Aldous Huxley, to think and discuss the crisis and transformations that the contemporary state is going through. As well as Huxley book allow us to rethink, through a literary point of view, the imminent transformations endured by society and state during the XX's century, surprisingly anticipating many aspects of today's consumption society, this paper investigates the most relevant elements in contemporary state's crisis and searches for possible alternatives for building a new model.
\end{abstract}

Key-words: Contemporary State - Crisis - Globalization - Brave New World - Aldous Huxley

Grandes obras de literatura política, tais como 1984, de George Orwell, Farenheit 451, de Ray Bradbury, e Admirável Mundo Novo, de Aldous Huxley - precursor do gênero, publicado já em 1932 -, impressionaram o século XX pela capacidade de antever as tendências totalitárias pelas quais os Estados nacionais passariam. Em seu conjunto, essas obras são valorizadas não somente por seus aspectos literários, criativos, mas

\footnotetext{
1 Mestre em Direito (UNISINOS). Doutoranda em Direito (UNISINOS) Advogada. Professora (CESUCA/UNISINOS). E-mail: rmgubert@,terra.com.br 
também pela profundidade com que abordaram temas de fundamental relevância para o pensamento político: liberdade, igualdade, democracia, entre outros.

O grande impacto que essas narrativas futuristas ainda provocam nos dias atuais se justifica, em grande parte, por seu caráter quase profético - já na década de 30 do século passado, anteciparam realidades improváveis e hoje plenamente possíveis, tais como a reprodução humana em laboratório. Entretanto, essas virtudes também são acompanhadas por um inevitável sentimento de angústia; como todo pensamento crítico, o convite a uma reflexão profunda sobre os destinos do Estado e da sociedade fatalmente geram um certo estranhamento.

Assim como no início do século passado, as transformações causadas por grandes eventos históricos, como as duas grandes Guerras Mundiais (1914/1918 e 1939/1945), a Revolução Russa (1917) e a crise econômica provocada pelo crash da bolsa de Nova Iorque (1929), entre outros, apontaram para significativas transformações na estrutura, no funcionamento e no papel do Estado Nacional, a passagem do século XX para o século XXI também desponta mudanças necessárias e irreversíveis.

A investigação acerca das transformações do Estado contemporâneo - diante de novos desafios geopolíticos e econômicos, tais como a globalização, o capitalismo financeiro, o terrorismo, as crises ambientais, entre outros - e, especialmente, a abertura para se pensar novos modelos de governo não fundados, necessariamente, na concentração de poder na figura do Estado constitucional e seus tradicionais elementos (povo, território e governo soberano) exigem, assim como na leitura de um Admirável Mundo Novo, um exercício consciente de enfrentamento dessa angústia causada pelo abandono de um modelo já conhecido, mas inevitavelmente esgotado.

Obras de autores como David Held (Cosmopolitismo e Modelos de Democracia), Jacques Chevallier (O Estado Pós-Moderno), Michael Hardt e Antonio Negri (Império, Multidão e Comune), Georg Sorensen (La transformación del Estado), Saskia Sassen (Territory, Authority, Rights: from medieval to global assemblages), Pierre Rosanvallon (La Legitimidad Democrática), entre muitos outros, refletem sobre temas centrais da filosofia política - tais como democracia, soberania, elementos do Estado moderno, constitucionalismo, Estado de bem-estar social - e apontam para insubsistência desse modelo diante do contexto atual. Além disso, são trabalhos de grande esforço criativo, na medida em que, além de analisar a formação histórica e o cenário existente, são propositivos, e buscam vislumbrar novas instituições e formas de organização capazes de atender mais adequadamente às exigências presentes e futuras. 
Embora vistos com certo ceticismo e preocupação, impressões decorrentes da forte identificação histórica que a Teoria do estado e a Teoria da Constituição estabelecem com a noção de Estado constitucional como locus privilegiado para a proteção de direitos fundamentais, tais autores e suas teorias sofrem, inicialmente, o preconceito que recai sobre todos que assumem uma posição de vanguarda. Nesse sentido, Admirável Mundo Novo é um excelente exemplo literário para se debater as possibilidades de um futuro improvável que irremediavelmente se confirma como realidade.

Não podemos olvidar que o termo Estado, aplicado em seu sentido moderno, por si só já designa uma instituição histórica e geograficamente situada. Como explica J. J. Canotilho, o termo Estado, mesmo sem adjetivos, carrega consigo um sentido profundo de historicidade, indissociável do processo ocidental da modernidade (CANOTILHO, 2002, p. 26-27).

\begin{abstract}
Basta um breve relance de olhos pela vasta literatura jurídica, política e económica relacionada com o Estado para verificarmos esta intriga: o Estado do não está só. Tem sempre o acompanhamento de adjectivos. À guisa de um curto inventário, apresentamos algumas adjectivações: "estado subsidiário", "estado sobrecarregado", "estado dispensador de serviços", "estado activo", "estado económico", "estado-arena", "estado desobediente", "estado aberto", "estado cooperativo", "estado protector", "estado garantidor", "estado desfronteirizado", "estado internacional", "estado cosmopolítico", "estado ponderador", "estado cooperativo", "estado ecológico", "estado argumento", etc. Pela lista assim esboçada, poderemos ver que nem sequer a sobrecarregámos com adjectivos tradicionais, como "estado de direito", "estado democrático", "estado autoritário", "estado social", "estado liberal", "estado intervencionista", "estado socialista", "estado unitário", "estado regional", "estado federal", "estado republicano", "estado nação". Quando vemos o Estado cercado de adjectivos, talvez se possa dizer o que Carl Schmitt afirmou acerca da Constituição. Mais ou menos isto: um Estado carecedor de adjectivos indicia um claro mal-estar do próprio Estado. Parece não ter substância. Apela a algumas qualidades. É tudo e nada.
\end{abstract}

A obra de Aldous Huxley trabalha com a ideia de uma sociedade perfeita, de felicidade plena e geral; o tema das sociedades utópicas foi perseguido por pensadores desde a antiguidade clássica ( $A$ República, de Platão) até Renascimento (Utopia, de Thomas More). A diferença essencial é que a sociedade do mundo depois de Ford é distópica (LLOSA, 2004. p. 119-120). No contexto do século XX, as sociedade planificadas e centralizadas não são mais vistas como o paraíso, mas, ao contrário, se fundam pela instituição do terror e do medo e instalam no indivíduo uma sentimento inconsciente de ausência de sentido e desespero profundo, mascarado por uma aparência de felicidade externamente produzida. Aos personagens capazes de perceber seu contexto de aprisionamento em uma sociedade totalitária, resta uma profunda solidão e isolamento. 
Todos são felizes, porém nem todos são iguais (LLOSA, 2004, p. 123). Ainda que na teoria as sociedades utópicas representem um Estado que assegura a felicidade de todos, o governo fica sempre a cargo de uma aristocracia, de uma grupo restrito de pessoas tidas por mais qualificadas (qualificação que pode ser intelectual, econômica, social, religiosa); curiosamente, no caso do Admirável Mundo Novo a superioridade é genética. Existe apenas um partido e o governo é permanente. As classes não são econômicas ou sociais; são genéticas.

Entretanto, é possível afirmar com razoável correção que a crítica de Huxley não antevia, de forma tão dianteira, a sociedade contemporânea; sua narrativa, em realidade, antecipa um futuro próximo, o próprio século XX, e pensa as possibilidades de sucesso, e os problemas dele decorrentes, da eventual vitória, de um sobre o outro, entre os dois grandes modelos econômicos que disputavam o cenário econômico, político e ideológico do início do século. De forma muito intrigante, sua obra pode ser interpretada tanto como uma crítica ao capitalismo, como ao socialismo.

Diferentemente de Orwell, que compromete seus textos 1984 e Revolução dos Bichos, com uma crítica aberta às experiências dos regimes socialistas, especialmente na União Soviética, Huxley mistura elementos do socialismo totalitário, tais como a existência de um único partido, a unificação do mundo com apenas um único sistema de governo - os dez Administradores Mundiais -, o fim da religião, a censura aos livros clássicos, o esvaziamento das relações familiares, com outros elemento de crítica ao capitalismo e ao american way of life: consumo, descartabilidade de objetos e relações, dependência à substâncias de alívio psíquico, excessiva higienização e assepsia, imposições estéticas etc.

O Estado totalitário do mundo pós-Ford está fundado na certeza científica. Os seres humanos são bebês de proveta, produzidos em laboratório, e recebem a carga genética minimante necessária para desempenhar as atividades para as quais o Estado prédetermina. A família e a maternidade/paternidade (vínculo de formação da criança com seus pais) são trocadas pelo Centro de Incubação e Condicionamento. Os impulsos e os comportamentos são manipulados e condicionados nos primeiros anos de vida das crianças. A curiosidade natural e o pensamento crítico são extirpados por um processo ao qual as crianças eram submetidas (HUXLEY, 2001, p. 52-53):

- Coloquem os livros - disse ele, secamente. Em silêncio, elas obedeceram à ordem. Entre os vasos de todas, os livros foram devidamente dispostos - uma fileira de livros infantis pequenos, cada um aberto, de modo convidativo, em 
alguma gravura agradavelmente colorida, de animal, peixe ou pássaro. - Agora, tragam as crianças. Elas saíram apressadamente da sala e voltaram ao cabo de um ou dois minutos, cada qual empurrando uma espécie de carrinho, onde, nas suas quatro prateleiras de tela metálica, vinham bebês de oito meses, todos exatamente iguais (um Grupo Bokanovsky, evidentemente) e todos (já que pertenciam à casta Delta) vestidos de cáqui. - Ponham as crianças no chão. Os bebês foram descarregados. - Agora, virem-nas de modo que possam ver as flores e os livros. Virados, os bebês calaram-se imediatamente, depois começaram a engatinhar na direção daquelas massas de cores brilhantes, daquelas formas tão alegres e tão vivas nas páginas brancas. Enquanto se aproximavam, o sol ressurgiu de um eclipse momentâneo atrás de uma nuvem. As rosas fulgiram como sob o efeito de uma súbita paixão interna; uma energia nova e profunda pareceu espalhar-se sobre as páginas reluzentes dos livros. Das filas de bebês que se arrastavam engatinhando, elevaram-se gritinhos de excitação, murmúrios e gorgolejos de prazer. O Diretor esfregou as mãos. Excelente! - comentou - Até parece que foi feito sob encomenda. Os mais rápidos engatinhadores já haviam alcançado o alvo. Pequeninas mãos se estenderam incertas, tocaram, pegaram, despetalando as rosas transfiguradas, amarrotando as páginas iluminadas dos livros. O Diretor esperou que todos estivessem alegremente entretidos. Depois disse: - Observem bem. - E, levantando a mão, deu o sinal. A Enfermeira-Chefe, que se encontrava junto a um quadro de ligações na outra extremidade da sala, baixou uma pequena alavanca. Houve uma explosão violenta. Aguda, cada vez mais aguda, uma sirene apitou. Campainhas de alarme tilintaram, enlouquecedoras. As crianças sobressaltaram-se, berraram, suas fisionomias estavam contorcidas pelo terror.

Desse forma, criava-se uma aversão aos comportamentos tidos por inconvenientes ou perigosos à manutenção da ordem e da estabilidade. A obsessão das utopias releva, assim, sua maior intenção: suprimir a desordem e a irracionalidade. Mas a completa planificação tem seu preço: o desaparecimento da liberdade (LLOSA, 2004, p. 123). Somente Mustafá Mond, o controlador da Europa Ocidental, possui uma biblioteca secreta na qual guarda os livros clássicos da cultura ocidental greco-romana.

O sonho da sociedade ideal não nasce do altruísmo, da generosidade ou dos sentimentos mais levados; no fundo, trata-se de um retorno à escravidão, do retrocesso a um estado de completa submissão e falta de responsabilidade, uma volta à felicidade plena do homem, que antecede ao nascimento do próprio indivíduo (LLOSA, 2004, p. 124).

No mundo proposto por Huxley, fundado na exaltação/divinização de Ford, o Estado é superior ao indivíduo, razão pela qual este - como uma engrenagem - deve se colocar a serviço do primeiro. Talvez, no século XX, essa visão totalitária melhor tenha se adequado aos problemas decorrentes dos regimes socialistas, como uma denúncia à supressão das liberdades individuais e do direito discordar da ideologia imposta pelo partido (singular!). Entretanto, no século XXI é muito atraente comparar essa hegemonia de uma ideologia dominante com a força avassaladora da expansão do capitalismo financeiro e o sequestro das economias nacionais, cativas das especulações do mercado internacional. 
Sem dúvida, esse processo de transformação econômica, que arrasta como em uma inundação, a autonomia dos Estados nacionais e o poder de regulação de suas Constituições, foi e é viabilizado pela Globalização. Mas o desafio, de certa forma, não mudou: continuamos debatendo a necessidade de construir e manter os ideais da democracia, antes ameaçada pela governos autoritários, e hoje pelo enfraquecimento dos sistemas de direito dos Estados nacionais diante de novas instâncias de poder, detentoras do capital especulativo e que não conhecem os limites das fronteiras nacionais.

$\mathrm{Na}$ atualidade, a globalização é um processo inevitável. Dentre os desafios impostos, uma das questões mais caras ao futuro do Estado e do direito é a questão da democracia e da manutenção de um constitucionalismo capaz de assegurar os direitos fundamentais (individuais e, principalmente, o financiamento dos direitos sociais diante de um discurso de insustentabilidade financeira que já virou "lugar comum"). O "termo globalização traduz a existência de uma nova dinâmica que, escapando muito largamente ao controle dos Estados, atinge todos os países e toca todos os níveis de organização social [...] a interdependência sempre cada vez maior das sociedades tende a desenhar a imagem de um "mundo sem fronteiras" (CHEVALLIER, 2009, p. 33), de uma "sociedade global". Chevallier esclarece que a globalização pode ser compreendida pela conjugação de cinco grandes mutações (CHEVALLIER, 2009, p. 33):

\footnotetext{
a globalização dos mercados, que transforma a competição entre economias em competição entre sociedades; a globalização da comunicação, que cria formas inéditas de comunicação social; a globalização cultural, que aumenta o número de autores; a globalização ideológica, marcada pela imposição da vulgata liberal; a globalização política, que se traduziu na difusão de determinados modelos de organização política;
}

A economia torna-se elemento fundamental de análise para pensar e planejar as transformações do Estado contemporâneo; as teorias do Estado e da Constituição não podem mais ser estudadas de forma isolada, torna-se necessária uma profunda reflexão no campo da de filosofia política, capaz de reinventar um Estado - se esta for a nova forma de organização política que irá despontar no horizonte do futuro próximo - que consiga firmar os compromissos com a democracia e os direitos fundamentais em uma sociedade agora governada pelos interesses do capitalismo financeiro e dos mercados especulativos, que subvertem a lógica moderna do Estado como instância centralizadora do poder e da tomada de decisões. 
Novamente com Chevalier podemos entender os efeitos produzidos pela economia sobre o Estado constitucional (CHEVALLIER, 2009, p. 33-34):

\begin{abstract}
Antes de tudo, a economia mundial entrou numa nova era: a da "globalização". Ela se caracteriza pela conjugação de três elementos: um mercado unificado, em virtude da constituição de uma zona única de produção e de comércio; empresas globalizadas, gerando sobre uma base planetária a concepção, a produção e a distribuição de seus produtos e serviços; enfim, mecanismos de regulação permitindo dominar os fluxos econômicos em escala mundial.
\end{abstract}

Portanto, a globalização é acima de tudo uma globalização econômica e a força do sistema econômico é um vetor que necessariamente condiciona o funcionamento do Estado. Esse processo de atrelamento ou de dependência do Estado à economia (que agora é praticada em nível mundial, sem quaisquer restrições de fronteiras ou regulamentação jurídica pelos imobilizados estados soberanos), acaba por gerar um processo de desconstitucionalização, ou seja, os estados constitucionais e suas instituições supostamente soberanos - não tem mais o monopólio - ou em muitos situações a liberdade para participar - da decisão.

Nesse contexto, a democracia também se coloca como prioridade. No cenário atual, o maior desafio é identificar com clareza quais são as instituições e quem são os reais detentores do poder. Quem decide e quais são os interesses do capital? Ou seja, como desenvolver uma nova teoria do Estado e da Constituição, adequada à globalização e ao esvaziamento dos poderes do Estado, de forma a assegurar a participação democrática do cidadão?

Outro elemento sublime de Admirável Mundo Novo, e talvez a grande alternativa de salvação intuída por Huxley para a reabilitação da subjetividade no mundo desumanizado de Ford, é a personagem John, o Selvagem, filho de Linda e Thomas (diretor de incubação), fruto de uma relação carnal.

Enquanto a predeterminação genética e o condicionamento psicológico buscam extirpar da população a capacidade de pensar sua própria existência e, portanto, sentir o inexorável sentimento humano de angústia, próprio da condição humana que questiona o sentido da vida, o selvagem, repleto de mundo interno e subjetividade, rompe a assepsia e a esterilidade do mundo civilizado. Criado em um mundo de liberdade e caos, o imaginário de John é preenchido por resquícios da sociedade em que vivemos, cresceu lendo as obras de Shakespeare e a bíblia. Mas o romance de Huxley não é otimista. O conflito entre os mundos civilizado e bárbaro levam John ao suicídio. 
De qualquer sorte, podemos fazer uma interessante aproximação desse resgaste do selvagem de Huxley com a trilogia Império (Impero, 2000), Multidão (Moltitudine, 2004) e Comum (Comune, 2009), de Michael Hardt e Antonio Negri, na qual a proposta de um projeto ético da ação política democrática passa pela multidão dos pobres e sua forma de amor.

Forte ponto, que aproxima pelas diferenças, Admirável Mundo Novo e a trilogia de Hardt e Negri, é a questão do amor. Na narrativa literária, o amor (assim como outros sentimentos) foi quimicamente excluído, e perdeu por completo o sentido de existir, uma vez que também não mais existem as relações familiares e fraternais; os relacionamentos humanos se tornam superficiais e descartáveis, e o sexo promíscuo é incentivado pelo governo. A liberdade sexual nada tem a ver com subjetividade ou erotismo, trata-se quase do esporte nacional, mais uma atividade descartável que preenche o vazio dos dias prédefinidos (LLOSA, 2004, p. 121):

\footnotetext{
No entanto atenção, atenção, essa liberdade sexual não tem nada a ver com erotismo; diria-se que é, sim, sua negação. No planeta Ford, o sexo é higienizado em excesso, isento de todo o risco, mistério e violência para que a ginástica copulativa que praticam seus habitantes coincida com o que entendemos por erotismo, que dizer, o amor físico enriquecido e sutilizado pela fantasia humana. Em Admirável mundo novo, a função do sexo não é individual, mas social, o que indica que foi desnaturalizado.
}

Já na construção do projeto de uma nova sociedade, fundada no respeito à alteridade e na busca do comum, o amor passa a ser um conceito essencial da filosofia e da política. Não se trata do amor sentimental. Mas da forma de amor própria dos pobres, isto é, a solidariedade: o cuidado com o outro, a possibilidade da criação de uma comunidade e da cooperação em projetos comuns. A falta desse tipo de amor é causa central para a fragilidade do pensamento contemporâneo. $\mathrm{O}$ amor é o coração vivo do projeto de Hardt e Negri. Entretanto, o sentido de pobreza aqui empregado precisa ser contextualizado, ser pobre não é viver uma "vida nua", mas sim usar dos poderes de invenção e produção. Logo, a essência do pobre não é a "falta", mas sim o "poder" (HARDT; NEGRI, 2011, p.179-180).

Para os autores, sendo a República um projeto fundado na propriedade, os pobres então estão excluídos dela. Esse conflito não se estabelece pela dicotomia ricos e pobres, mas envolve mais profundamente a questão da produção da subjetividade. A propriedade privada cria uma subjetividade individual, que se unifica como classe apenas para proteger este direito. Nesse contexto, a multidão dos pobres não quer reclamar da sua miséria, mas 
sim romper, no sentido de criar uma nova subjetividade que resulta de uma radicalidade plural e de um corpo político aberto. O pobre não é aquele que nada tem, mas todos aqueles que estão inseridos na ampla multiplicidade dos mecanismos de produção social, independentemente da propriedade (HARDT; NEGRI, 2011, p. 39-40).

Partindo de uma análise de que a república é uma instituição histórica, criada essencialmente para proteger a propriedade - república da propriedade -, Hardt e Negri afirmam que a moderna dicotomia capitalismo e socialismo é perniciosa, porque em ambas alternativas os "regimes de propriedade excluem o comum" (HARDT; NEGRI, 2011, p. IX). A proposta dos autores é no sentido de que o rompimento com os fundamentos da modernidade e a construção de um novo modelo político, adequado ao paradigma da altermodernidade $^{2}$ (HARDT; NEGRI, 2011, p. 101), depende da ação de rebeldia e rompimento por parte dos excluídos, sejam eles os selvagens de Huxley ou os pobres e excluídos da contemporaneidade.

\section{REFERÊNCIAS}

AVELÃS NUNES, António José. O Estado Capitalista e as suas máscaras. Lisboa: Avante, 2013.

BOLZAN DE MORAIS, Jose Luis. As crises do Estado e da Constituição e a transformação espaço-temporal dos direitos humanos. 2. ed. Porto Alegre: Livraria do Advogado, 2011.

CANOTILHO, José Joaquim Gomes. O Estado adjetivado e a Teoria da Constituição. Revista da Procuradoria-Geral do Estado, v. 25, n. 56, 2002, Porto Alegre, ProcuradoriaGeral do Estado do Rio Grande do Sul, p. 25-40.

CHEVAlLIER, Jacques. O Estado Pós-Moderno. Belo Horizonte: Fórum, 2009.

GARCIA-PELAYO, Manuel. Las transformaciones del Estado contemporãneo. Madrid: Alianza Editorial, 1996

HARDT, Michael; NEGRI, Antonio. Commonwealth. Cambridge: Harvard University Press, 2011.

HARDT, Michael e NEGRI, Antonio. Comune. Oltre il privato e ili publico. Milano: Rizzoli. 2009.

\footnotetext{
${ }^{2}$ Altermodenidade tem uma relação diagonal com a modernidade, pois aponta mais claramente as forças de resistência no sentido da autonomia. Com o termo, os autores querem uma quebra definitiva com a modernidade.
} 
HARDT, Michael e NEGRI, Antonio. Moltitudine. Milano: Rizzoli. 2004.

HARDT, Michael e NEGRI, Antonio. Impero. Milano: Rizzoli. 2000.

HELD, David. Cosmopolitismo: ideales y realidades. Madrid: Alianza Ed, 2012..

HELD, David. Modelos de Democracia. 3. ed. Madrid: Alianza Ed, 2009.

HUXLEY, Aldous. Admirável Mundo Novo. 2. ed. São Paulo: Editora Globo, 2001.

LLOSA, Mario Vargas. A verdade das mentiras. São Paulo: Arx, 2004.

MORE, Thomas. Utopia. São Paulo: Rideel, 2005.

ORWELL, George. A revolução dos bichos. São Paulo: Companhia das Letras, 2007.

ORWELL, George. 1984. 29. ed. São Paulo: Companhia Editora Nacional, 2005.

PLATÃO. A República. 2. ed. São Paulo: Escala, 2007.

POSNER, Richard A. Law and Literature. Cambridge: Harvard University Press, 1998.

ROSANVALLON, Pierre. La Legitimidad Democrática: Imparcialidad, reflexividad y proximidad. Barcelona: Paidós, 2010.

SASSEN, Saskia. Territory, Authority, Rights: from medieval to global assemblages. Princeton: Princeton University Press, 2008.

SORENSEN, Georg. La transformación del Estado. Más allá del mito del repliegue. Valencia: Tirant lo Blanch. 2010.

STIGLITZ, Joseph. Globalização: como dar certo. São Paulo: Companhia das Letras, 2007.

(Artigo submetido em 08/07/2014 e aceito em 28/07/2014) 